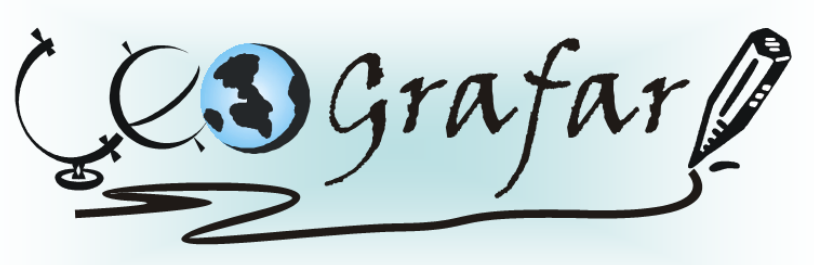

Revista Eletrônica do Programa de Pós-Graduação em Geografia - UFPR

\title{
A SACRALIZAÇÃO DA NATUREZA E A SIMBOLOGIA DA MORTE: A RESSIGNIFICAÇÃO DA PAISAGEM RELIGIOSA NOS CEMITÉRIOS DE ANJOS DE SÃO JOÃO MARIA
}

\section{THE SACRED NATURE AND DEATH SYMBOLOGY: THE REDEFINITION OF THE RELIGIOUS LANDSCAPE ON ANGELS CEMETERIES OF SÃO JOÃO MARIA}

\author{
(Pesquisador convidado) \\ Alcimara Aparecida Föetsch \\ Pós-doutora em Geografia pela Universidade Federal do Ceará \\ Professora da Universidade Estadual do Paraná campus de União da Vitória \\ alcimaraf@yahoo.com.br
}

\section{Resumo}

Quando se fala em São João Maria, Santo beatificado pelo povo no Sul do Brasil, são comuns várias referências a rituais de cura, batismo, oferendas, rezas e promessas que alimentam uma paisagem religiosa sui generis marcada pela sacralização dos elementos da natureza: o pocinho (ou olho d'água) que batiza/cura e a árvore de cedro (Cedrela fissilis) que brota quando plantada em forma de cruz. Todavia, no município paranaense de São Mateus do Sul um componente diferenciado deste cenário se torna recorrente e, estranhamente, não é mencionado na literatura regional. São os cemitérios de anjos e/ou cemitérios de criancinhas, pequenas sepulturas de natimortos ou recémnascidos que destoam da paisagem do entorno e despertam reflexões sobre o espaço ritualmente construído, o significado da morte, a topofilia, a religiosidade, o simbolismo, o patrimônio e o abandono. Nestes campos santos objetivou-se captar a materialidade visível por meio da leitura da paisagem enquanto texto decodificando os elementos que a compõe e apreender a dimensão intangível destes lugares de memória por meio da oralidade. Os rumos teórico-metodológicos seguiram as orientações da Fenomelologia, da Geografia Cultural e da Pesquisa Qualitativa, na perspectiva da Religião, com a intenção de investigar de que forma os lugares sagrados associados a São João Maria foram sendo ressignificados para além da sacralização da natureza pela simbologia da morte. Por fim, percebeu-se que a devoção à João Maria e os cemitérios de anjos, patrimônio cultural único, são expressões de resistência temporo-espaciais, percebê-los, visibilizá-los e estudá-los significa reconhecer uma religiosidade popular que, não institucionalizada, deu conta de criar e recriar distintas formas de expressar suas crenças cotidianas materializando-as na paisagem e as resguardando na memória.

Palavras-chave: São João Maria; Cemitério de anjos; Lugar simbólico; Ressignificação; Resistência. 


\begin{abstract}
When São João Maria is mentioned, beatified saint by the people of southern Brazil, a lot of references are common in healing rituals, baptism, offerings, prayings and promises that feed the religious landscape sui generis marked by the sacralization of nature elements: the "pocinho" (water eye) that baptisms/heals and the cedar tree (Cedrela fissilis) that sprouts when planted in the cross format. However, in the city of São Mateus do Sul a different component of this scenery becomes recurrent and, strangely, not mentioned in the regional literature. It is about the angels' cemetery and/or children's cemetery, small graves of stillbirths or newborns that disrupt the surrounding landscape and awakens reflections about the space ritually built, the death meaning, the topophilia, the religiosity, the symbolism, the patrimony and abandonment. In these holy fields it was aimed to capture the visual materiality through landscape reading while text decoding the elements that compose and seize the intangible dimension of these memory places through orality. The theoretical-methodological paths followed the orientations of Phenomenology, Cultural Geography and the Qualitative Research, in the region perspective, aiming at investigating in what ways the holy places linked to São João Maria were being redefined beyond the nature sacralization and death symbology. Finally, it was noticed that the devotion to São João Maria and the angels' cemeteries, unique cultural patrimony are expressions of resistance in terms of time and space, noticing them, making them visible and study them means to recognize a popular religiosity that, even not institutionalized, managed to create and recreate distinct formats to express their everyday beliefs, materializing them in the landscape and protect them in the memory.
\end{abstract}

Keywords: São João Maria; angels' cemetery; symbolic lace; redefinition; resistance.

\title{
Introdução
}

São muito comuns na região Sul do Brasil histórias sobre as passagens, profecias e predições de São João Maria, figura mítica, emblemática e heroica que foi canonizada pelo povo. A ele são atribuídos milagres de cura, devoções populares de um catolicismo rústico e um legado único de estórias, lendas e crenças que originaram um patrimônio sui generis. Capelinhas, cruzes, árvores de cedro, altares domésticos, oratórios e fontes de água estampam a paisagem religiosa alimentada pela peregrinação constante a estes lugares sagrados. Entretanto, no município de São Mateus do Sul/PR, esta sacralização dos elementos da natureza divide espaço com pequenas sepulturas infantis ressignificando os lugares.

O novo elemento em questão provoca reflexões sobre o espaço ritualmente construído, 0 significado da morte, a vida ancestral, a topofilia, a religiosidade, o patrimônio, as expressões de resistência e o abandono: são os cemitérios de anjos ou cemitérios de criancinhas. Numa formação acadêmica marcada pela influência da Geografia Cultural tal particularidade não passou despercebida e desencadeou um verdadeiro turbilhão de conexões teórico-metodológicas cujas tramas e proposições iniciais fluíram para vários horizontes: cultura popular, patrimônio material e intangível, representações sociais, cartografia de memória, política pública, pesquisa qualitativa, educação patrimonial; contudo, cada propositura ia sendo rejeitada ao passo que se percebia, pelas imersões de campo, que este objeto de pesquisa exigia um dimensionamento de análise capaz de retratar sua 
espacialidade vinculada ao jogo de forças no qual se inscrevia: era possível e necessário sobrepor o véu da religião para compreender que a fé popular e o catolicismo rústico emergiam também como uma expressão de perseverança e resistência.

A partir daí os questionamentos foram se desenhando: Como investigar o sagrado em sua dimensão espacial decodificando a paisagem religiosa? De que forma o significado da morte e a referência à ancestralidade transforma e alimenta os espaços? Onde se encaixa a topofilia na construção e vivência da sacralidade no cotidiano? Quais os elementos que formam este patrimônio cultural tangível e intangível? É possível propor uma Educação Patrimonial consoante com o espaço vivido? $\mathrm{E}$, assim, redimensionando os questionamentos e os alinhando à perspectiva teóricometodológica assumida, construiu-se a seguinte problemática: "De que forma os espaços sagrados associados a São João Maria foram sendo ressignificados da sacralização da natureza pela simbologia da morte"?

Tratam-se de lugares que, impregnados de simbolismo, não foram meramente descobertos, fundados ou construídos. Foram e são, de certa forma, reivindicados, possuídos e operados pela comunidade, não se tratam de santuários sublinhados por suntuosidade, opulência ou grandiosidade, ao contrário, são grutas e pequenos lugares que contrastam e destoam das paisagens do entorno, mas que resistem e são alimentados pela fé em "São" João Maria e pela necessidade humana de materializar suas crenças. São lugares de resistência, patrimônios que reivindicam olhares sensíveis, afinados e ajustados a um contexto histórico-social marcado por ausências, distanciamentos e carências.

Nesta perspectiva, a crença em João Maria e a ressignificação de seus espaços sagrados são discutidos de forma a evidenciar o processo ressemantizador do Santo e a dinâmica simbólica do culto à vida ancestral nos cemitérios de anjos. Por fim, a patrimonialização é apontada enquanto desafio e potencialidade na preservação das memórias coletivas e na salvaguarda da paisagem religiosa.

\section{Os espaços sagrados e a paisagem religiosa na perspectiva da Geografia Cultural}

Por um tempo significativo a Geografia resistiu em considerar aspectos do mundo vivido, das realidades culturais e, em especial, das representações religiosas, pode-se dizer que os geógrafos hesitaram em aprofundar estudos onde o concreto desaparecia rapidamente em favor das representações. Foi a partir da utilização das abordagens que se valem da Fenomenologia como base filosófica que a Geografia começou a superar a produção de uma história natural das paisagens partindo a conceber estudos acerca da forma com que os homens representam o espaço e a natureza bem como considerar a inserção dos grupos no meio e, assim, a tarefa do geógrafo passou a ser, 
portanto, dupla: explorar o universo das representações mentais e entender sua tradução para a paisagem (CLAVAL, 1992).

Em sua análise Heidrich (2016) esclarece que sob a denominação de Geografia Cultural há um grande espectro de temas de estudo, entre eles "o simbolismo das paisagens, o estudo de percepções e representações do espaço, as identidades territoriais, estudos de gênero, religiões e festas" (p. 20). Rosendahl (2012) acrescenta que a Geografia Cultural pós 1970 preocupa-se com o simbolismo, 0 conceito de lugar, os objetos na paisagem e a identidade cultural e Corrêa (1998) complementa que a partir do viés Humanista o lugar passa a ser um conceito-chave relevante e a paisagem torna-se um conceito valorizado, contribuindo para que os geógrafos não negligenciem a dimensão cultural do que observam e ultrapassem as barreiras das descrições e dos inventários.

Pereira e Gil Filho (2012) especificam que é "na fase moderna, já meados do século XX, que a Geografia, sob tutela científica, começa a abordar o fenômeno religioso de maneira mais sistemática" (p. 03) e, dessa maneira, evidenciam-se os estudos da Geografia da Religião, enquanto subcampo (ou ramo, para Fickeler, 1999) da Geografia Cultural, que busca investigar os espaços sagrados e suas múltiplas interpretações a partir de um conjunto de abordagens teóricas centradas nas dimensões do simbolismo e de um direcionamento teórico-metodológico centrado na percepção do fenômeno religioso frente aos lugares sagrados. Isso porque Geografia e religião são duas práticas sociais, a primeira porque analisa o espaço, e a segunda porque enquanto fenômeno cultural ocorre espacialmente (ROSENDAHL, 1995a) e nas palavras de Sopher (1967, p. 24) "uma das preocupações da geografia da religião é entender como a paisagem se associa a um conjunto de sistemas religiosos e modelos de religiosidade que estão condicionados a comportamentos".

Neste sentido, Rosendahl (1996) levanta dois importantes questionamentos: Como se define 0 estudo geográfico da religião? Como investigar o religioso pela via geográfica? E Rosendahl (2012) coloca que a Geografia da Religião "deve ser compreendida como o estudo da ação desempenhada pela motivação religiosa do homem em sua criação e sucessivas transformações espaciais" (p. 25), acrescentando-se que a religião "sempre foi parte integrante da vida do homem, como se fosse uma necessidade sua para entender a vida" (ROSENDAHL, 1995b, p. 45) e que ambas, Geografia e Religião, se conectam por meio da dimensão espacial.

Esta conjunção abarca o conceito de sagrado, cuja palavra significa separação e definição, sugere sentido de ordem, totalidade e força. Sagrado, por si só, é um conceito religioso, pois "está no centro de um sistema de práticas (positivas e negativas), isto é, funciona como regulador do agir social dos membros e como integrador da sociedade" (MARTINELLI, 1995, p. 162), sendo assim, emerge como uma categoria de interpretação e avaliação que existe como tal apenas no campo religioso. 
Espaços sagrados são espaços qualitativamente fortes, "onde o sagrado se manifestou" (ROSENDAHL, 1995b, p. 63), sendo que, para o homem religioso, essa manifestação pode se conter em um objeto, pessoa ou lugar. Portanto, o homem religioso se exprime sob formas simbólicas que se relacionam com o espaço e suas práticas religiosas se realizam em tempos e lugares simbólicos, pois a "manifestação de poder do sagrado em determinados lugares o diferencia dos demais" (ROSENDAHL, 1995b, p. 67) e este reflete percepções singulares, que variam entre os grupos, visto que, os "povos têm atribuído sacralidade a diferentes objetos como árvores sagradas, pedras, grutas com poderes milagrosos, uma fonte de cura, um túmulo em volta do qual ocorrem milagres" (p. 68).

É por meio de símbolos, mitos e ritos que o sagrado exerce sua função de mediação entre o homem e a divindade e essa manifestação é indicada pelo termo "hierofania", que "etimologicamente significa algo de sagrado que se revela" (ROSENDAHL, 1995a, p. 98). E, assim, percebe-se que os lugares não só se diferenciam por formas e cores, por racionalidades funcionais e econômicas, mas, também, são carregados de essências e significam muito mais do que o sentido geográfico de localização, é onde o homo religiosus busca manter-se em proximidade com o universo sagrado (ELIADE, 2001).

Para Tuan (1979), sagrado é tudo que se destaca do lugar comum e da rotina, dessa forma, cada comunidade religiosa recorda o espaço à sua maneira, de forma a constituir um ponto fixo em que ela se confina, onde ela reencontra suas lembranças, contribuindo, assim, com o florescimento de sentimentos de apego e afetividade para com o espaço vivido, relações topofílicas (TUAN, 1980). A manifestação do sagrado, por sua vez, multiplica-se em inúmeros espaços sagrados, que são os santuários, onde o espaço se torna sacro e cujo conjunto mitológico é a própria memória da religião, ressaltando que seria bastante difícil evocar o acontecimento se não houvesse o lugar do ocorrido, por isso, são também chamados de "lugares simbólicos" (ROSENDAHL, 2009), ou seja, espaços criados pela ocupação humana "e pelo uso de símbolos para transformar aquele espaço em lugar" (p. 06), por sua vez, a "geografia define o espaço sagrado como um campo de forças e de valores que elevam o homem religioso acima de si mesmo, transportando-o para um lugar distinto daquele no qual transcorre seu cotidiano" (p. 07).

Compreender a essência desses lugares sagrados implica realizar a leitura da paisagem religiosa que é portadora de significados, expressa valores, crenças, mitos e utopias tendo assim uma dimensão simbólica (CORRÊA; ROSENDAHL, 1998, p. 08), pois "os símbolos ganham maior força e realce quando estão impregnados de afetividade e significação no lugar religioso. A representação simbólica existe em si mesma e se materializa no espaço". (ROSENDAHL, 2003, p. 206). Isto posto, concorda-se que a paisagem, terreno fértil para os geógrafos culturais (COSGROVE; JACKSON, 
1987), pode ser analisada na perspectiva do lugar sagrado e sua dimensão simbólica, como nos cemitérios de anjinhos de São João Maria.

\section{A construção metodológica - trabalho de campo, paisagem religiosa e lugar simbólico}

Os espaços sagrados são lugares onde a dimensão cultural tangível, expressa na paisagem religiosa, ultrapassa a materialidade visível e alcança uma perspectiva transcendental em que se acredita atingir a mediação com a divindade ou com a vida ancestral. $\mathrm{Na}$ audaciosa aventura de compreender a forma com que se dá esse encontro e decodificar a ressignificação destes espaços, são necessários parâmetros metodológicos adequados a um nível de realidade que não pode ser quantificado, uma vez que se trata de um "universo de significados, motivos, aspirações, crenças, valores e atitudes, o que corresponde a um espaço mais profundo das relações, dos processos e dos fenômenos que não podem ser reduzidos à operacionalização de variáveis" (MINAYO, 1994, p. 21-22).

Por possuir uma identidade própria para muito além do não quantitativo, a Pesquisa Qualitativa se apresenta como uma alternativa viável na medida em que busca esmiuçar "a forma como as pessoas constroem o mundo à sua volta, o que estão fazendo ou o que está lhes acontecendo" (BANKS, 2007, p. 08), em lugares que não são somente repositórios de memória, mas que foram sendo moldados por experiências de vida.

No âmbito da Ciência Geográfica, Heidrich (2016) acrescenta que são as geografias que lidam com as práticas sociais e culturais que reclamam o uso das metodologias qualitativas, compreendidas pelo autor como sendo uma "prática ou conjunto de procedimentos voltados à coleta de informações que envolvem o uso da linguagem, em geral objetivadas para a captura de subjetividades e/ou significados contidos nos textos produzidos no levantamento em trabalho de campo" (HEIDRICH, 2016, p. 22), sendo que o trabalho de campo é o "método definitivo de várias disciplinas etnológicas (como, por exemplo, a antropologia, a etnobotânica, a etnomusicologia, os estudos de performance, a etnometodologia e os estudos da religião)" (HARVEY, 2017, p. 170).

Partindo deste horizonte metodológico, as primeiras investigações da presente pesquisa iniciaram-se em agosto de 2016 por meio das atividades do Instituto Histórico e Geográfico de São Mateus do Sul (IHG/SMS) quando foi elaborado um relatório de pesquisa, com fins exploratórios, sobre São João Maria e seus lugares. Contou-se com a colaboração de moradores do município e da região do entorno que foram fornecendo indicações de lugares. Utilizou-se da técnica de coleta de dados conhecida como snowball (bola de neve, HANDCOCK; GILE, 2011) ou cadeia de informantes, que consiste em uma amostragem não probabilística, uma espécie de rede de informação ou cadeia de referência, utilizada nas pesquisas sociais onde os primeiros informantes contatados (sementes) vão 
amealhando novos até se chegar ao ponto de saturação, quando não surgem mais novas indicações, somente repetições.

Foram, dessa forma, realizados trabalhos de campo em 43 diferentes lugares indicados pelos informantes. Destes, 10 foram desconsiderados por se tratarem de marcas na paisagem em forma de cruzes, capelinhas e marcos históricos distintos não reconhecidos pelas comunidades como associados a São João Maria. Dos 33 lugares que efetivamente se associam ao Santo popular no município de São Mateus do Sul, 13 deles possuem cemitérios de anjos e um total de 07 foram selecionados para o aprofundamento da pesquisa. Esta seleção desconsiderou os que se encontram abandonados e desgastados pelo tempo e priorizou uma distribuição que contemplasse diferentes comunidades atestando a abrangência espacial no município, conforme o Mapa 01 :

Mapa 01: Lugares sagrados associados a São João Maria, no município de São Mateus do Sul/PR.

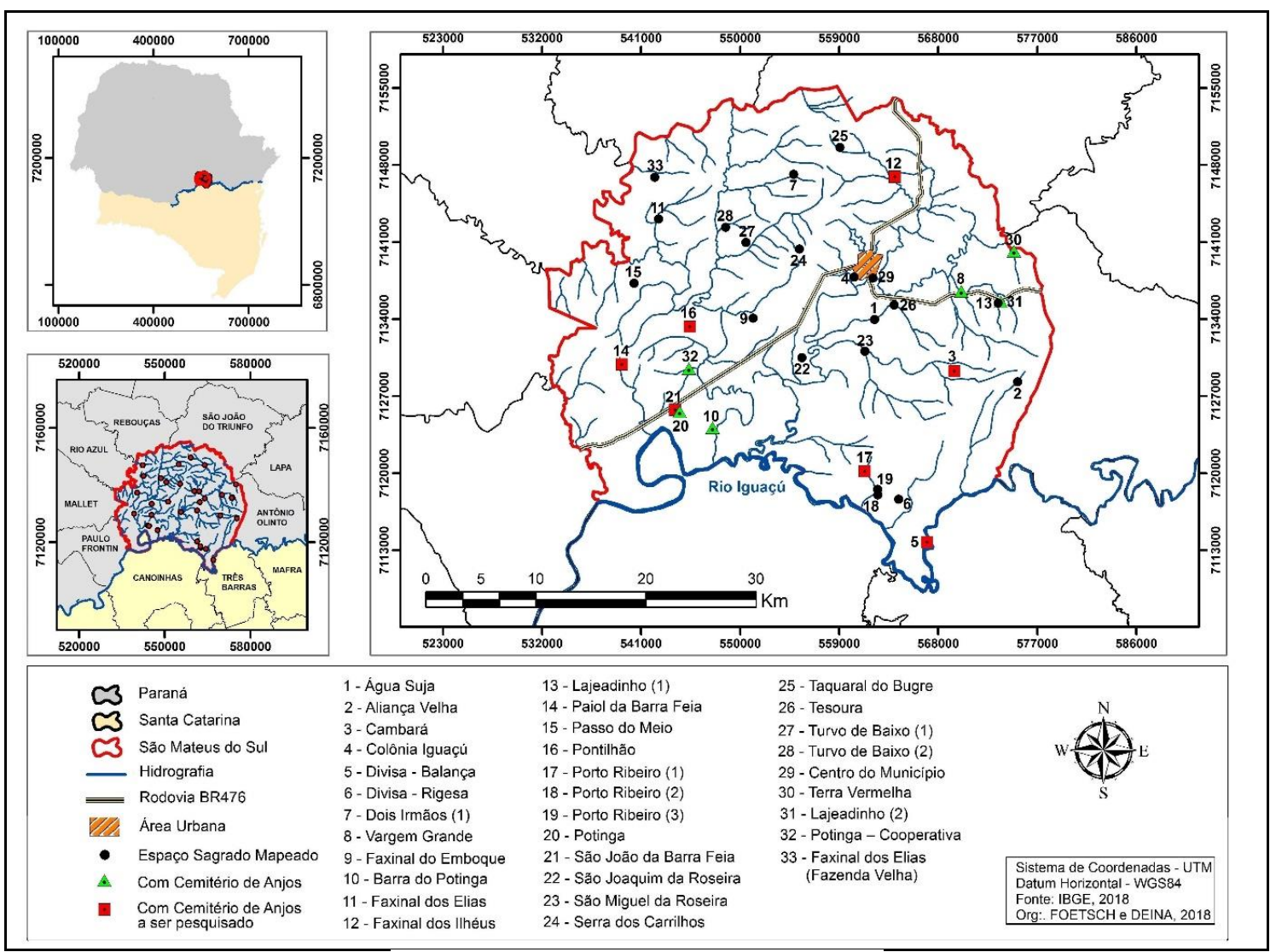

Fonte: Organizado pela Autora, 2018.

As Fotos 01 a 09 ilustram os espaços sagrados selecionados: 


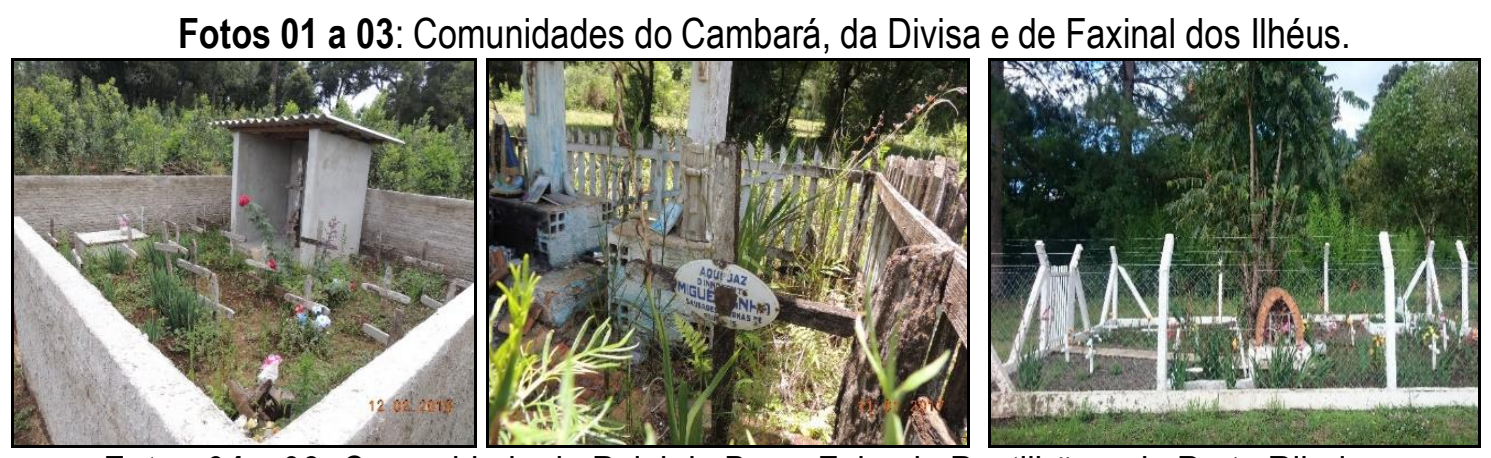

Fotos 04 a 06: Comunidade do Paiol da Barra Feia, do Pontilhão e do Porto Ribeiro.
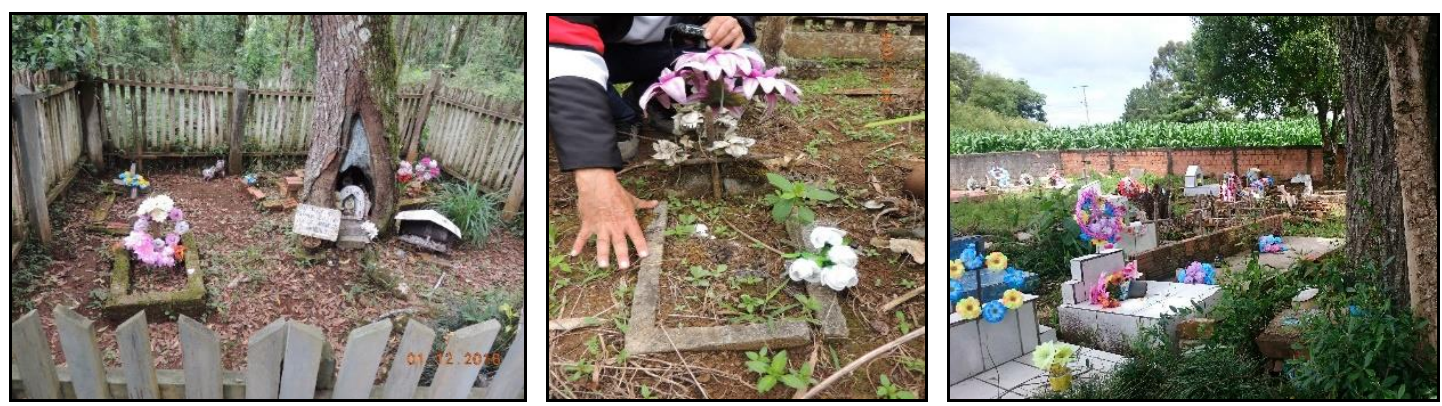

Fotos 07 a 09: Comunidade de São João da Barra Feia.
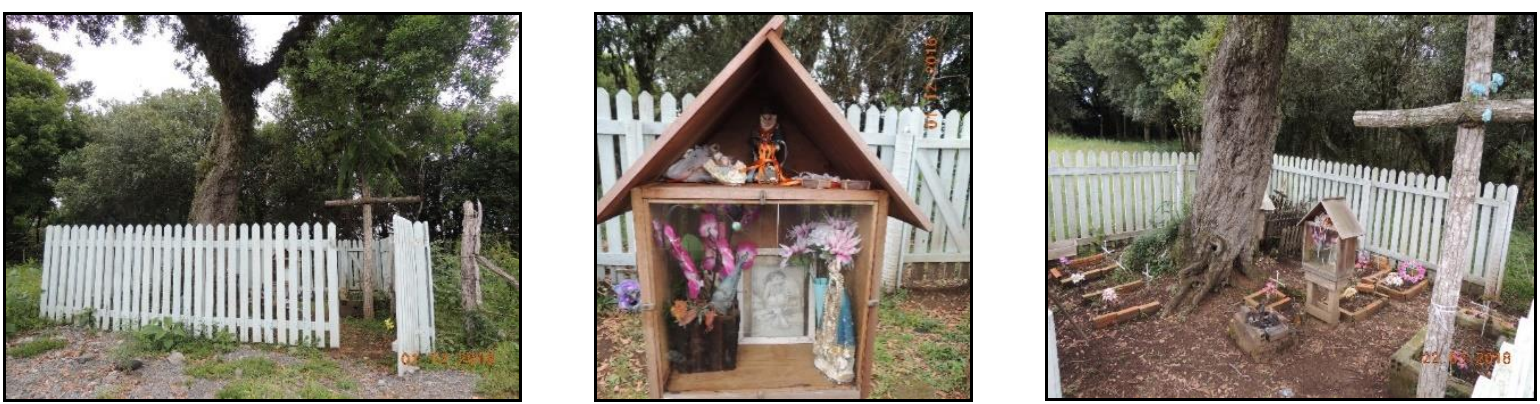

Fonte: Trabalho de campo da Autora, 2016 a 2018.

Decodificar a paisagem religiosa presente nestes espaços sagrados implicou considerar duas dimensões de análise:

a) Material ou tangível: expressa visualmente na materialidade do lugar e constituída pelos elementos e objetos palpáveis da paisagem religiosa. Consiste em uma abordagem interdisciplinar que não a vê somente como sistema de criação de símbolos, mas como texto que permite múltiplas leituras, nas palavras de Duncan (2004) a paisagem, elemento central no sistema cultural, é "um conjunto ordenado de objetos, um texto, age como um sistema de criação de signos" (p. 106);

b) Imaterial ou intangível: que são as abstrações e os significados atribuídos ao lugar pelos que vivenciam as práticas religiosas, constituem "lugares de memória", que segundo Nora (1993) são "com efeito, nos três sentidos da palavra, material, simbólico, funcional" (p. 21), ou seja, cenários que permitem revisitar o passado, histórias que impregnam o meio, pois a "a memória se enraíza no concreto, no espaço, no gesto, na imagem, no objeto" (p. 09). 
Ambas dimensões, articuladas, encaixadas e impossíveis de serem dissociadas, permitiram desvendar os elementos que construíram e alimentam essa paisagem religiosa, desembraçando os nós do tempo e compreendendo as afetividades e relações que ressignificaram estes lugares.

\section{Os "cemitérios de anjos" - a ressignificação da paisagem religiosa de São João Maria}

João Maria, personagem, figura lendária e simbólica, é mito que reuniu e congregou uma síntese da trama social vivenciada a partir da segunda metade do século XX no Sul do Brasil, em especial, na região centro-sul do Paraná e no planalto norte catarinense, um cenário marcado pela "impregnação religiosa na vida cotidiana" (MONTEIRO, 1974, p. 84) onde líderes messiânicos preenchiam o vazio deixado pela Igreja e pelo Estado. Distribuía orações, receitava chás e infusões, benzia roças, santificava fontes de água, "plantava" cruzes de cedro, orientava sobre onde viver, era conselheiro, árbitro, juiz, encorajava o trabalho na terra. Na crença popular fazia milagres e "as árvores sob as quais descansava passavam a ser veneradas, rosários e fitas pendiam de seus galhos. As fontes em que bebia adquiriam virtudes terapêuticas" (QUEIROZ, 1965, p. 248).

Profeta que era, antes de mais nada, "um intérprete" como sugere Gallo (1999, p. 177) é hoje mosaico e ícone construído e desenhado por várias mãos. É visto como a representação de uma realidade social e percebido como princípio estruturante comum. É evento fundante na medida em que, canonizado pelo povo com atribuída imortalidade, representa hoje, simbolicamente, diferentes expressões de resistência. Dentre as inúmeras possibilidades analíticas acerca destes significados e percorrendo os caminhos da religiosidade, percebe-se que os lugares sagrados atribuídos a São João Maria e venerados historicamente consistem em paisagens excluídas e marginalizadas por não conterem aspectos estéticos de beleza e modernidade.

Esta materialização do sagrado associada a sacralização da natureza se dá pequenos lugares que, longe de serem majestosos santuários, resistem espremidos pelo agronegócio, pelo reflorestamento, pela modernidade e pelo esquecimento. São espaços que evocam a nostalgia de um passado mitificado, geram pertencimento e sedimentam recordações de um tempo histórico onde a cura física e o conforto espiritual provinham da fé nas ofertas da natureza. São lugares simbólicos que foram fundados religiosamente, o que "possibilita criar uma aura de proteção ao ambiente e às pessoas, promove uma espécie de sacralização do lugar" (WELTER, 2012, p. 100).

Cruzes e águas santas são conjunção comum nos espaços sagrados de São João Maria, porém, em São Mateus do Sul, no Paraná, o cemitério de anjos/criancinhas, adiciona um forte elemento identitário agregador, de vívido apelo afetivo. Difícil determinar o início de cada cemitério de anjos, sobretudo, porque os primeiros a realizarem essa prática já faleceram, restando apenas os que 
reproduzem os sepultamentos pela devoção a João Maria e pela consideração aos costumes ancestrais. No recorte espacial analisado ficou evidente que esta prática fúnebre se relaciona diretamente ao Santo popular tendo em vista que muitos relatam que o próprio São João Maria havia "dado ordem" para enterrar os anjinhos em seus lugares de pouso, por serem lugares "valiosos".

Estes "anjinhos" eram, principalmente, recém-nascidos natimortos, fetos que nasciam antes do tempo e, em casos menores, crianças até sete anos de idade. De início, acreditava-se que eram chamados de anjos por não terem sido batizados, isso procede em alguns relatos, porém, muitos descrevem que a Igreja, justamente por sua relativa ausência nestes sertões interioranos, não impedia o sepultamento em seus cemitérios. Dessa forma, percebeu-se que o que deu origem aos cemitérios de anjinhos foi, sobretudo, a crença na proteção de João Maria, (lembrando que muitos eram seus afilhados reais ou espirituais) do que o fato de não terem sido oficialmente abençoadas pelo batismo da fé cristã. Portanto, "anjos" são os que nasciam mortos (natimortos), faleciam logo após o nascimento, por vezes ainda sem identificação clara do sexo ou crianças que morriam antes dos sete anos de idade. Quando não se sabia ainda o sexo, durante o batismo em casa ou no próprio cemitério, eram atribuídos nomes duplos que mesclavam o feminino e o masculino, como Maria José, ou, muito comum, João Maria. $O$ enterro era feito pela própria família, pela parteira ou por conhecidos próximos, sem documentação oficial de nascimento e óbito.

Somam-se a isso, as justificativas acerca das dificuldades encontradas na região durante estes anos iniciais do século XX, em especial, a falta de estradas trafegáveis, a precariedade de transportes e as intempéries do tempo que dificultavam o translado destas crianças até os campos santos mais distantes. Entretanto, há que se mencionar o fato de que os adultos, independente destas condições, eram levados até os cemitérios oficiais.

Neste sentido, é necessário pontuar que a expansão de crenças e práticas religiosas populares no início do século XX em São Mateus do Sul/PR se deu por uma série de motivos intimamente relacionados ao contexto social e econômico da época na região do Contestado (FRAGA, 2006) e seu entorno: ausência da medicina oficial, distanciamento das instituições eclesiásticas, expropriação de terras, dominação coronelista, choque cultural entre indígenas, caboclos e imigrantes, exploração estrangeira, insegurança em relação ao governo republicano, entre outros. Este cenário era sentido e percebido na ausência de escolas, desemprego, abandono por parte do Estado, altas taxas de mortalidade (sobretudo, infantil), falta de estrutura comunitária e, principalmente, "atribuída" ignorância religiosa do povo, referindo-se ao catolicismo rústico não reconhecido como verdadeiro e autêntico pela aristocracia monopolista cristã (QUEIROZ, 1965). 
Emerge, desta forma, uma estrutura social propícia ao desenvolvimento de crenças messiânicas e, João Maria, evento fundante, irrompe justamente neste conturbado período e passa a representar resistência, princípio estruturante comum. Vira símbolo, mártir, era padrinho em vida, criou e alimentou laços de compadrio pelo apadrinhamento espiritual que neste contexto social significava proteção, acolhimento, abrigo, amparo e assistência. Os lugares que the serviram de abrigo foram santificados, recebendo o status de "espaço sagrado de São João Maria". São lugares de encontro, de fé, peregrinação e particularização com a santidade, distinto dos lugares de confronto cercados de obrigações institucionalizadas que excluem a maioria.

Lugares que foram sendo ressignificados na medida em que a devoção à São João Maria, tradicional em seus lugares de pouso, foi acrescido do culto à vida ancestral por meio dos cemitérios de anjinhos. A paisagem religiosa abriga, então, não só promessas e ex-votos, mas também oferendas que reverenciam os laços de parentesco e amizade com os que tiveram curta passagem por este mundo, nasceram para não viver. A materialidade do visível na paisagem cria um verdadeiro sistema de significações em uma estampa religiosa que, entendida como texto, revela e evidencia manifestações espaciais da religião que simbolizam a resistência de uma fé popular rústica desenhada autêntica e espontaneamente. Com 0 acréscimo dos cemitérios de anjos, os lugares são ressignificados pela adição do culto à vida ancestral, lamentações e memórias. As sepulturas reordenam a tradicional conjunção entre cruzlágua santa.

Nestes locais, são comuns romarias e rituais de fé que denotam uma particularização com a santidade em forma de batismos, promessas, oferendas, rezas e cerimônias. São visíveis velas, coroas de flores, bilhetes, rosários, imagens de santos, crucifixos, flores, bíblias, fotos, formas que representam partes do corpo, fitas, ou seja, a simbolização material (signos) das imagens e das crenças. Trata-se de um espaço ritualmente construído, onde se processa o encontro com a divindade e com a vida ancestral.

É a manifestação intangível da religião também em sua condição de materialidade e, neste sentido é impossível concluir uma análise do espaço sagrado na perspectiva geográfica, sem pautar uma discussão acerca destes lugares enquanto expressões de resistência temporo-espaciais. Isso implica interpretar o cenário que, propício ao surgimento e consolidação da crença em João Maria, foi e ainda é marcado por uma realidade socioeconômica e política excludente, elitizada e institucionalizada que domina, explora, marginaliza e desvaloriza. Significa compreender o papel de uma religiosidade popular que, desabrochando em um contexto social complexo, reflete os anseios de um povo carente de assistência espiritual eclesiástica e distante das ações do Estado que encontra nas práticas culturais tradicionais uma forma de atenuar suas angústias. 
As décadas avançam e a presença física de João Maria não mais é concreta e material, foi a ele atribuída a imortalidade, hoje é percebido e evocado como "uma entidade ambivalente (humana e não humana ao mesmo tempo). Ao afirmar que não pode ter morrido porque é 'um santo homem' ou 'profeta de Deus', reforça-se a noção de que João Maria é uma entidade com potencialidades semelhantes a Jesus Cristo e Deus" (WELTER, 2012, p. 101), o mito passa, então, por "um processo ressemantizador - de santo legitimado, passou a líder político atualizado" (p. 105).

\section{Considerações Finais}

Desvendar, em campo (sendo o campo instrumento de análise geográfica) a dinâmica destes lugares simbólicos por meio da associação da paisagem como texto e dos lugares de memória, exigiu um aparato metodológico diverso que foi se construindo, também, ao longo da pesquisa, lembrando que para Morin (2005) o método só pode emanar e se formular após o conhecimento do recorte espacial e sua especificidade. Dessa forma, percebeu-se que se tratava de um universo que não poderia ser quantificável, era preciso lidar com a oralidade para, em seguida, destrinchar os significados e sentidos, desembaraçando os nós e compreendendo as afetividades para com o espaço sagrado, repositório das recordações - e, só assim, harmonizar e fundir os aspectos tangíveis da paisagem à imaterialidade da memória. Desse modo, o discurso, o enredo, as predições e profecias ofereceram o suporte.

Os anjinhos, os nascidos para não viver, evidenciam e reforçam não só a crença na proteção do Santo popular como também promovem uma série de questionamentos acerca da ressignificação destes lugares simbólicos. Frutos de abortos espontâneos, natimortos, falecidos pouco tempo após 0 nascimento, ou crianças até sete anos de idade, foram, diferente dos adultos, enterrados junto às cruzes e águas seguindo "ordens" do próprio profeta canonizado pelo povo e com atribuída imortalidade. São, de fato, paisagens marginalizadas por não conterem aspectos estéticos de beleza, proporção e elegância, mas que, no entanto, vivificam lembranças e promovem experiências emocionais/espirituais, o que constitui o campo das motivações simbólicas, um verdadeiro sistema de significações.

A cruz, símbolo e signo da experiência religiosa rústica, é escudo mágico contra os perigos, plantada por João Maria, ao brotar do cedro, testemunha o poder extraordinário do divino. A água pura, elemento central no ritual do batismo e da purificação, cura, protege, fertiliza, espanta os males e dá proteção. Dois elementos da natureza, fios condutores, Axis Mundi para Eliade (2001), riquezas da região, dividem o espaço com cruzes menores em tamanho que testemunham e representam na paisagem os anjinhos falecidos, alguns, até afilhados espirituais de João Maria - os laços de apadrinhamento constituem outra inquietação. Estes lugares, dessa forma, se ressignificam e passam 
a receber por conta deste elemento agregador de forte valor afetivo, outras formas de culto e peregrinação pelo acréscimo de oferendas distintas, orações e cuidados aos que se foram: filhos, irmãos, netos, sobrinhos, conhecidos.

Diferentemente dos adultos, esses anjinhos cuja brevidade da vida não permitiu pecar, são carinhosamente depositados junto à João Maria invocando a proteção do Santo que tanto auxiliou nos momentos de necessidade. A partir desta adição, a dinâmica deste lugar simbólico se diferencia e passa a assumir também função de lembrança, referência e encontro - é a paisagem religiosa evocando memórias e sentimentos, texto que pode ser interpretado. Velas, coroas de flores e orações são direcionadas aos anjinhos ao mesmo tempo em que promessas, ex-votos e oferendas de agradecimento são direcionados ao Santo, ressaltando que Tuan (1979) já afirmava que cada comunidade religiosa opera e recorda o espaço sagrado à sua maneira, contribuindo para o florescimento de relações topofílicas de apego e afetividade (TUAN, 1980).

Mesmo acreditando que laços de parentesco familiar próximo constituem fortes vínculos afetivos, encontrou-se ao longo da pesquisa de campo, os cemitérios de anjinhos em lugares de culto à João Maria descuidados, abandonados e até esquecidos. Ao passo que, em outros lugares, foi possível perceber um esforço coletivo das comunidades em garantir a proteção, preservação e visibilidade destes espaços sagrados, juntamente com a valorização da crença e das memórias associadas ao Santo e às crianças falecidas. Tais extremos despertaram reflexões adicionais acerca do patrimônio cultural, tanto material quanto intangível, a complexidade e as dificuldades na patrimonialiação destes lugares. À medida que muitos já desapareceram ou estão prestes a se extinguir, outros foram "reformados", ou seja, remodelados, na melhor das intenções, entretanto, numa perspectiva de modernização cujo estilo construtivo destoa da essência que se associa à natureza, à simplicidade, à harmonia do ambiente.

Se tratam de lugares que floresceram de forma a responder um contexto social carente e excludente, que não foi sintoma de descompasso cultural, mas expressão de resistência temporoespacial contrariando a lógica imposta de fazer aceitar situações de dependência, exploração e legitimação de instâncias. Neste cenário, durante mais de um século, João Maria, figura lendária como chamaria Rosendahl (1996), tornou-se a representação mítica religiosa, guia, inspirador e conselheiro que congregou a comunhão daqueles que compartilharam de seus ideais e, nas últimas décadas, passou por um processo ressemantizador, de santo legitimado à líder político atualizado (WELTER, 2012) contradizendo as previsões que afirmavam que a crença desapareceria com o advento da racionalidade científica e da modernização (TOMAZI, 2009). Perceber a ressignificação de seus lugares simbólicos comprova tais afirmações. 


\section{Referências}

BANKS, M. Dados visuais para pesquisa qualitativa. Porto Alegre: Artmed, 2007.

CLAVAL, P. Le thème de la religion dans les études géographiques. Géographie et cultures, Paris, $\mathrm{n}^{\circ}$ 2, 1992. (p. 85-110).

. A Geografia Cultural. Editora da UFSC: Florianópolis, 2014.

CORREA, R. L. Espaço: um conceito-chave da Geografia. In: CASTRO, I. E. de; CORREAA, R. L.; ROSENDAHL, Z. (Orgs.). Paisagem, tempo e cultura. Rio de Janeiro, EdUERJ, 1998.

CORREA, R. L.; ROSENDAHL, Z. (Orgs.). Paisagem, tempo e cultura. Rio de Janeiro: EdUERJ, 1998. COSGROVE, D.; JACKSON, P. New directions in cultural geography. Area 19(2), 1987 (p. 95-101). DUNCAN, J. A paisagem como sistema de criação de signos. In: Correa, R. L.; Rosendahl, Z. (Orgs.) Paisagens, textos e Identidades. Rio de Janeiro: Eduerj, 2004. (p. 90-132).

ELIADE, M. O Sagrado e o profano: a essência das religiões. São Paulo, Martins Fontes, $5^{\mathrm{a}}$ Tir. 2001. FICKELER, P. Questões fundamentais na Geografia da Religião. Revista Espaço e Cultura. nº. 7, 1999. (p. 7-36).

FRAGA, N. C. Mudanças e Permanências na Rede Viária do Contestado: uma análise acerca da formação territorial do Sul do Brasil, Tese (Tese de doutorado), Doutorado em Meio Ambiente e Desenvolvimento. Universidade Federal do Paraná, UFPR, 2006.

GALLO, I. O Contestado: o sonho do milênio igualitário. Campinas: Ed. da Unicamp, 1999.

HANDCOCK, M. S.; GILE, K. J. On the Concept of Snowball Sampling. Sociological Methodology, v. 41, n. 1, agosto de 2011. (p. 367-371).

HARVEY, G. Pesquisa de Campo: Observação Participante. In: Revista Rever. Ano 17, nº 01, jan./abr. de 2017. (p. 168-206).

HEIDRICH, Á. L. Método e metodologias na pesquisa das geografias com cultura e sociedade. In: HEIDRICH, Á. L.; PIRES, C. L. Z. (Orgs.) Abordagens e práticas da pesquisa qualitativa em geografia e saberes sobre espaço e cultura. Porto Alegre: Editora Letra1, 2016. (p. 15-33).

IHG/SMS. Instituto Histórico e Geográfico de São Mateus do Sul. São Mateus do Sul, Paraná, 2014. MARTINELLI, S. A religião na sociedade pós-moderna. São Paulo: Paulinas, 1995.

MINAYO, M. C. de S. (Org.). Pesquisa Social: teoria, método e criatividade. $17^{\mathrm{a}}$ ed. Petrópolis, RJ: Vozes, 1994.

MONTEIRO, D. T. Os errantes do novo século: um estudo sobre o surto milenarista do Contestado. São Paulo: Duas Cidades, 1974.

MORIN, E. O método 1: a natureza da natureza. $2^{a}$ ed. Tradução llana Heineberg. Porto Alegre: Sulina, 2005.

NORA, P. Entre a Memória e História: a problemática dos lugares. Tradução de Yara Aun Khoury, Projeto História, São Paulo: 1993.

PEREIRA, C. J.; GIL FILHO, S. F. Geografia da religião e espaço sagrado: diferenças entre as noções de lócus material e conformação simbólica. In: Revista Ateliê Geográfico. Goiânia-GO. v.06, n. 01, abril de 2012. (p. 01-17).

QUEIROZ, M. I. P. de. O messianismo no Brasil e no mundo. São Paulo: Alfa-Omega, 1965. ROSENDAHL, Z. Geografia da Religião. In: Boletim Gaúcho de Geografia, nº. 20, dez., 1995a. (p. $96-$ 99). 45-74).

Geografia e religião: uma proposta. In: Revista Espaço e Cultura, Ano 1, outubro de 1995b. (p. Espaço e Religião: uma abordagem geográfica. Rio de Janeiro: UERJ, NEPEC, 1996. . Espaço, cultura e religião: dimensões de análise. In: CORREAA, R.L. e ROSENDAHL, Z. (Orgs).

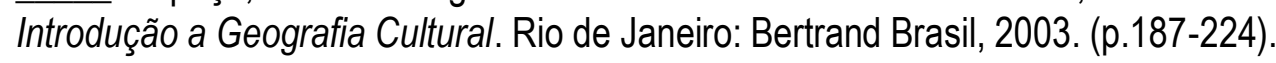


A dimensão do lugar sagrado: ratificando o domínio da emoção do ser-no-mundo. In:

CARNEIRO, S. de S.; SANT'ANNA, M. J. G. (Orgs.). Cidades, olhares e trajetórias. Rio de Janeiro: Garamond, 2009.

. História, teoria e método em Geografia da religião. In: Revista Espaço e Cultura. UERJ, RJ. n³1, jan.jun. de 2012. (p. 24-39).

SOPHER, E. E. Geography of Religions. Englewood Cliffs: Prentice Hall, 1967.

TOMAZI, G. Profecia e santidade: experiência religiosa de João Maria. Revista Pistis Prax., Teol. Pastor., Curitiba, v. 1, n. 1, jan./jun. 2009. (p. 89-118).

TUAN, Y. F. Sacred Space. Exploration of na idea. In: BUTZER, K. Dimension of Human Geography. Chicago: Chicago Research Paper, 1979.

1980.

. Topofilia: um estudo da percepção, atitudes e valores do meio ambiente. São Paulo: DIFEL,

WELTER, T. Discursos e interpretações contemporâneos em torno do profeta São João Maria. In:

Revista Esboços. v. 19, nº. 28. Florianópolis, dez/2012. (p. 88-111). 